\title{
Neosporose em Animais Domésticos
}

\section{Neosporosis in domestic animals}

\author{
José da Silva Guimarães Junior ${ }^{1 *}$; Paulo Roberto Romanelli
}

\section{Resumo}

\begin{abstract}
A neosporose, doença emergente causada pelo Neospora caninum, é considerada como a principal causa de abortamentos em bovinos em vários países. Estudos têm sido realizados até hoje com diversas espécies de animais, visando melhor elucidação da neosporose considerando agente, hospedeiro e meio ambiente. Esta revisão enfatiza aspectos sobre patogenia e diagnóstico da neosporose em alguns animais domésticos.
\end{abstract}

Palavras-chave: Neospora caninum. Bovinos. Cães. Ovinos. Eqüídeos.

\begin{abstract}
Neosporosis, emerging disease caused by Neospora caninum was considered the most important causes of aborts in cattle from many countries. Some studies have been developed in several animal species to understand host-parasite relationship. The present review describes some aspects about pathogeny and diagnostic of the neosporosis in domestic animals.
\end{abstract}

Key -words: Neospora caninum. Bovine. Dogs. Ovines. Horses.

\section{Introdução}

O N. caninum é um parasita morfologicamente semelhante ao $T$. gondii, porém, difere deste pelas características de ultraestrutura, imunogenicidade e patogenicidade (DUBEY; LINDSAY, 1993). Outros coccídios como Sarcocystis cruzi, Hammondia hammondi, Hammondia pardalis e Hammondia heydorni têm também estreita filogenia com o $N$. caninum (DUBEY et al., 1988). O parasita apresenta numerosas roptrias e se multiplica por endodiogenia. Os taquizoitos tem formato ovóide, lunar ou globular, com dimensões de 3 a 7 micrometros de comprimento por 1 a 5 micrometros de largura, conforme o estágio de divisão. Nos animais infectados são encontrados em células do sistema nervoso, macrófagos, fibroblastos, células do endotélio vascular, miócitos, células do epitélio dos túbulos renais e hepatócitos (DUBEY et al., 1988; DUBEY, 1993; BJERKAS; PRESTHUS, 1987; SPEER; DUBEY, 1989) .

Os taquizoítos penetram ativamente nas células hospedeiras em aproximadamente cinco minutos após o contato (HEMPHILL; GOTTSTEIN; KAUFMANN, 1996), sendo encontrados no citoplasma da célula, dentro ou fora de vacúolo parasitóforo. Apresentam dois anéis apicais, um anel polar, oito a 18 roptrias, complexo de Golgi, retículo endoplasmático rugoso e liso, um núcleo e um nucléolo (SPEER; DUBEY, 1989; LINDSAY et al., 1993). A discrepância no número de roptrias pode ser devido a dificuldade em distinguir roptrias de grânulos densos

1 Docente do Departamento de Medicina Veterinária Preventiva- Universidade Estadual de Londrina, Londrina- PR. E-mail: jsgj@uel.br.

2 Médico Veterinário Mestre em Ciência Animal pela Universidade Estadual de Londrina

* Autor para correspondência. 
(DUBEY, 1993). Microporos não têm sido encontrados nos taquizoítos em animais, porém presentes em taquizoítos provenientes de cultivo celular (SPEER; DUBEY, 1989; LINDSAY et al., 1993). Cistos teciduais arredondados ou elípticos, com até 107 micrômetros de diâmetro tem sido encontrados somente em células do sistema nervoso, como cérebro, medula espinhal, nervos e retina (DUBEY et al., 1988; DUBEY; KOESTNER; PIPER., 1990). A parede do cisto é lisa, medindo até quatro micras de espessura, dependendo do tempo de infecção. Na maioria dos cistos, ela varia de uma a duas micras, o que a diferencia do cisto de $T$. gondii o qual tem a parede com espessura menor que uma micra. No interior dos cistos encontram-se os bradizoítos, os quais são delgados, medindo seis a oito micrômetros de comprimento por um a 1,8 micrômetros de largura e contendo as mesmas organelas dos taquizoítos, exceto um menor número de roptrias e maior número de grânulos PAS positivos. Os oocistos medem de 10 a 11 micras de diâmetro, contem dois esporocistos com quatro esporozoítos cada um, esporulando no meio ambiente, em 24 horas (McALLISTER et al., 1998).

McAllister et al. (1998) e Gondim et al. (2004) demonstraram experimentalmente que cães e coiotes se constituem em hospedeiros definitivos do $N$. caninum e Basso et al. (2001) relataram o primeiro caso de um cão naturalmente infectado eliminando oocistos.

Cães e coiotes se infectam ingerindo tecidos de bovinos e de outras espécies as quais contenham cistos, além da ingestão de oocistos esporulados livres no meio-ambiente (transmissão horizontal). A transmissão vertical ou transplacentária é a forma mais freqüente de infecção por $N$. caninum (BJORKMAN et al., 1996; PARÉ; THURMOND; HIETALA, 1997; DAVISON; OTTER; TREES, 1999), sendo uma importante forma de manutenção do agente nos rebanhos. Devido ao fato da infecção fetal freqüentemente não resultar em abortamento, fêmeas podem nascer infectadas congenitamente e transmitir o agente para seus descendentes em futuras gestações (ANDERSON; ADRIANAVIRO; CONRAD, 2000). Esta modalidade de transmissão pode ocorrer por várias gestações (BJERKAS; MOHN; PRESTHUS, 1984; DUBEY et al., 1988; BARR et al., 1993).

O N. caninum tem sido encontrado parasitando naturalmente bovinos, ovinos, caprinos, bubalinos, canídeos (cães, raposas e coiotes), cervídeos e camelos. Infecções experimentais têm sido obtidas em suínos, leporinos felinos, canídeos (raposas, dingos e coiotes), roedores (camundongos, ratos e gerbils), raccoons e primatas.

\section{Neosporose em bovinos}

A infecção por $N$. caninum em bovinos tem sido reconhecida em todo mundo e é atualmente aceita como importante causa de abortamento em bovinos de corte e leite sendo a principal etiologia em países como o México (ABBIT et al., 1993), Dinamarca (AGERHOLM; BARR, 1994), Reino Unido (OTTER et al., 1995), Suécia (HOLMDAHL; BJÖRKMAN; UGGLA, 1995), Irlanda (McNAMEE; JEFFREY, 1994), Estados Unidos da América, Holanda e Nova Zelândia (McALLISTER et al., 1996; McALLISTER et al., 1998). Além disso, registros da doença são citados por Hornok et al. (1998) na Hungria, Campero et al. (1998) na Argentina, Paré et al. (1998) no Canadá, Huong et al. (1998) no Vietnam, Gottstein et al. (1999) na Suíça, Fondevila et al. (1998) e Gonzales et al. (1999) na Espanha. No Brasil, no estado da Bahia, Gondim et al.(1999) realizaram o primeiro estudo de soroprevalência do $N$. caninum em bovinos, ao examinarem soro sangüíneo de 447 vacas da raça Holandesa e mestiças, em 14 propriedades leiteiras do estado, sendo $80 \%$ dos animais constituído por vacas em lactação. Para o teste foi utilizado uma RIFI, de acordo com Conrad et al.(1993) e Yamane et al.(1997), com um título de 200 sendo considerado positivo para anticorpos de $N$. caninum. Anticorpos foram detectados em 63 (14,09\%) dos 447 soros testados. Os títulos obtidos nas amostras de soro 
foram: 200(18), 400(24), 800 (14), 1600 (5) e 3200 (2). Somente uma das 14 propriedades leiteiras não apresentou evidência sorológica de neosporose.

Ainda no Brasil, Ogawa (2000) ao analisar 385 amostras de soro de bovinos leiteiros da região norte do estado do Paraná pela RIFI observou um percentual de $11,69 \%$ de soropositividade para o N.caninum, não ocorrendo reação cruzada com o T.gondii. Guimarães Junior et al. (2004) estudaram fatores de risco para infecção por N.caninum em bovinos em nove municípios do norte do estado do Paraná, em propriedades produtoras de leite tipo B. A idade dos animais foi fator de risco para a ocorrência de anticorpos anti-N.caninum com maior número de bovinos positivos após os 24 meses de idade. No mesmo estudo a presença de cães positivos nas propriedades e a prevalência nos bovinos apresentaram correlação positiva fraca enquanto a produção de silagem e/ou concentrado na propriedade atuou como fator de proteção.

Historicamente, Thilsted e Dubey (1989) foram os primeiros a diagnosticar a neosporose em bovinos, embora outros autores já tivessem suspeitado dessa enfermidade (OTOOLE; JEFFREY, 1987; PARISH et al., 1987; SHIVAPRASAD; ELY; DUBEY, 1989). Yamane et al. (1997) relataram pela primeira vez, no Japão, o isolamento de N.caninum de tecidos neurais de um bezerro infectado congênitamente.

Fêmeas podem abortar a partir do terceiro mês de gestação. Lindsay et al. (1996) observaram variação entre o terceiro e o oitavo mês, sendo que a maioria dos fetos abortados examinados tinham idade gestacional entre quatro e seis meses. De acordo com Thornton, Gajadhar e Evans (1994), Anderson, Barr e Conrad (1994) e McAllister et al. (1996), os abortamentos ocorrem em forma de surtos ou esporadicamente, em qualquer estação do ano. Segundo Anderson et al. (1991) e Thurmond, Anderson e Blanchard (1995), a maioria dos abortamentos registrados na Califórnia ocorreram no período de inverno. Por outro lado, na Holanda, a maior taxa foi observada no verão Moen e Wouda ( apud DUBEY; LINDSAY, 1996).
Bezerros neonatos infectados apresentam os membros posteriores e/ou anteriores flexionados ou hiperestendidos, ataxia, diminuição do reflexo patelar, perda de consciência, exoftalmia, assimetria ocular e deformidades associadas com lesões de células nervosas, na fase embrionária. Alguns bezerros são incapazes de levantar-se desde o nascimento ou nas primeiras semanas de vida e, em outros casos, ocorre evolução favorável após determinado período de ataxia (PICOUX et al., 1998). É provável que a maioria dos bezerros com neosporose clínica morram dentro das primeiras quatro semanas de vida (DUBEY; LINDSAY, 1996).

Outras alterações patológicas consistem na reabsorção ou mumificação fetal e ainda, nascimento com aspecto clínico normal porém cronicamente infectado (DUBEY; LINDSAY, 1996; HOAR et al., 1996; DUBEY; SCHARES, 2006). O aparecimento dos sintomas em bezerros nascidos de mães infectadas ocorre em cerca de cinco dias após o parto (BARR et al., 1993), enquanto Dubey (1989) observou ainda mielite, miocardite e encefalite associado ao $N$. caninum, em bezerros infectados.

Duivenvoorden (1995) cita que bezerros podem nascer com distúrbios neurológicos ou desenvolvêlos alguns dias após o nascimento e, além disso, vacas com histórico de neosporose podem abortar novamente ou gerar bezerros infectados em próximas gestações. Barr et al. (1993) e Anderson et al. (1997) observaram ainda que a infecção e abortamento ocorrem em gestações consecutivas ou não.

O N. caninum é encontrado na maioria das vezes em cérebro, fígado e coração e raramente em outros órgãos, inclusive a placenta. Wouda et al. (1997) pesquisando o parasita em 80 fetos abortados, encontrou-o em cérebro ( 71 casos $=89 \%$ ), coração ( 11 casos $=14 \%)$ e fígado $(21$ casos $=26 \%)$, através de imunohistoquímica. Segundo Dubey e Lindsay (1996) não há dados sobre a localização preferencial do $N$. caninum no cérebro, portanto, para exame histológico qualquer parte ou fragmento do cérebro pode ser examinado. 
Bartels, Wouda e Schukken (1999) realizaram um estudo de caso controle com o objetivo de analisar fatores de risco para $N$. caninum associado a surtos de abortamentos, em 47 rebanhos leiteiros na Holanda. Os dados foram obtidos através de um questionário, considerando a situação nas propriedades dois anos antes do surto e incluiu 120 variáveis consideradas serem fatores de risco para introdução ou recrudescência da neosporose. Os dados foram analisados através de regressão logística condicional e apontaram como fatores significantes a presença de cães e aves, além da alimentação com silagem de milho úmida durante o verão. Uma afinidade linear foi encontrada entre o número de cães/aves e o risco avaliado para um surto de abortamentos. Outra associação significante encontrada foi entre a presença de cães e bovinos soropositivos nos rebanhos controle. A alimentação com silagem úmida foi considerado um fator de risco o qual pode induzir reativação de uma infecção latente por $N$. caninum devido a ingestão de micotoxinas que levam a imunosupressão.

Recentes estudos sorológicos tem sugerido que títulos $\geq 200$ (RIFI) são específicos para infecção por $N$. caninum (DUBEY et al., 1996), porém títulos maiores tem sido sugeridos para o diagnóstico de abortamentos ( TREES et al., 1993). Existe indicações que títulos sorológicos podem decair rapidamente após o abortamento (CONRAD et al., 1993) e, deste modo, a escolha de um de ponto de corte e época da realização do teste são fundamentais para um diagnóstico exato.

Segundo Cox et al. (1998), altos títulos de anticorpos anti $N$. caninum declinam rapidamente após o abortamento, mas baixos títulos positivos persistem por um tempo prolongado.

Hietala e Thurmond (1999) alertaram para cuidado especial dos pesquisadores quando da interpretação dos resultados sorológicos para $N$. caninum em bovinos na faixa etária entre 13 e 24 meses de idade, devido a possibilidade de resultados falso negativos, em virtude do declínio de anticorpos, nesta idade, em animais infectados congenitamente.
Stelund et al. (1999) na Suécia, realizaram um estudo com o objetivo de caracterizar como os níveis de anticorpos se alteraram durante o período de gestação, em bovinos naturalmente infectados com o $N$. caninum e, relacionar isto á performance reprodutiva. A amostragem foi constituída por soro sangüíneo de 80 novilhas leiteiras as quais foram amostradas mensalmente durante toda a gestação, sendo que em 13 delas o processo de colheita foi repetido na segunda gestação. $\mathrm{O}$ teste foi realizado através do Iscom ELISA tendo sido usado um ponto de corte de $\mathrm{DO}=0,20$. Todos os animais triados apresentaram valores de absorbância acima de 0,4, em cada amostragem. A média dos valores de absorbância de vacas que não abortaram seguiu um padrão uniforme durante ambas gestações, com aumento no quarto a quinto mês antes do parto, seguido por uma diminuição próximo ao parto. Um padrão semelhante de títulos de anticorpos com um pico 4 - 5 meses antes do parto foi também observado nas gestações que terminaram em abortamento. $\mathrm{O}$ número médio de inseminações destas novilhas foi de 1,7 e 2,2 vezes na primeira e segunda gestação, respectivamente. Um total de 7 (23\%) de 31 gestações terminaram em abortamento ou natimorto, com 3 abortamentos durante a primeira gestação, 2 durante a segunda e um bezerro natimorto na primeira e segunda gestações.

Investigações epidemiológicas realizadas na Califórnia, Holanda e Nova Zelândia indicaram que aproximadamente $20 \%$ de todos os fetos abortados, submetidos a diagnóstico laboratorial, foram positivos para N.caninum. Em casos de abortos em rebanhos leiteiros com história de abortamento endêmico por Neospora, a proporção de infecção nos fetos abortados foi de $44 \%$ (ANDERSON; ADRIANAVIRO; CONRAD, 2000).

Anderson, Adrianaviro e Conrad (2000) realizaram uma investigação sorológica em um rebanho leiteiro em Maryland (EUA), constituído por 1029 animais, independente de idade, sexo e história clínica. O rebanho consistiu de 113 bezerros, 280 novilhas, 168 novilhos e 465 vacas, e tinha histórico 
de abortamento endêmico e crônico não diagnosticado há 25 anos. Foram colhidas amostras de sangue de todos os animais e, para avaliação da presença de anticorpos para $N$. caninum, foi utilizada a RIFI em diluição única de 1:200 como título de ponto de corte. A soroprevalência total do rebanho foi de 28\%. Dentro do rebanho, 20,6\% das bezerras em bezerreiro, $30,7 \%$ das bezerras adolescentes em estábulo, 39,0\% das novilhas e $26,0 \%$ das vacas apresentaram anticorpos para $N$. caninum. A prevalência em bezerros machos foi de $15,6 \%$ no bezerreiro e $21,8 \%$ em estábulo, enquanto que os índices de prevalência em machos e fêmeas adolescentes estabulados foi de $21,8 \%$ e $30,7 \%$, respectivamente.

Na Carolina do Sul, Jenkins et al. (2000) avaliaram comparativamente os testes sorológicos RIFI, r-ELISA, iscom ELISA e NAT, utilizando amostras de sangue de 240 vacas da raça Holandesa com dois a 10 anos de idade, que encontravam-se sofrendo um surto de abortamento associado ao $N$. caninum. Os resultados obtidos com a RIFI (1:25) e Iscom ELISA $(0,20)$ foram respectivamente $77 \%$ (185/240) e 79\% (190/240) de positividade. Com relação ao NAT e r-ELISA, a percentagem de positivos oscilou de acordo com o título do ponto de corte utilizado. Para o NAT os autores utilizaram títulos de 40, 80 e 160 e obtiveram índices de positividade de $91 \%$, 62\% e $35 \%$, respectivamente, enquanto que no r-ELISA, ao utilizarem títulos de 1000, 1500 e 2000, alcançaram índices de 89\%,74\% e $63 \%$, respectivamente.

Sawada et al.(2000) no Japão, isolaram pela primeira vez o $N$. caninum de uma vaca infectada naturalmente. $\mathrm{O}$ animal pertencia a raça Holandesa, com 2 anos de idade e sofreu 2 abortamentos com infecção por Neospora confirmada. O animal apresentou título de 1600 para anticorpos anti $N$. caninum pela RIFI e foi sacrificado 24 dias após o segundo abortamento. Homogeneizado do cérebro foi inoculado intraperitonealmente em 3 camundongos, os quais desenvolveram paralisia e foram necropsiados 46 dias após a inoculação. Os cérebros dos camundongos foram inoculados em cultivo celular de células Vero. Como resultado da necrópsia da vaca, nenhuma lesão grosseira foi encontrada nos tecidos, sendo a principal lesão a presença de nódulos gliais no SNC, enquanto os 3 camundongos apresentaram infecção sistêmica por N. caninum, com a presença de taquizoítos em vários órgãos como cérebro, pâncreas, coração, glândulas adrenais, estômago e músculo esquelético. Quanto ao cultivo celular, taquizoítos foram detectados 39 dias após a inoculação com o homogeneizado de cérebro dos camundongos. Para a confirmação foi realizado um PCR destes taquizoítos o que resultou em infecção por N. caninum.

Baillargeon et al. (2001) no Canadá, estudaram a transferência de embrião para receptoras soronegativas, usando o procedimento definido pela Sociedade Internacional de Transferência de Embrião (IETS), para prevenção de transmissão vertical de N.caninum em bovino. Foram selecionados 3 grupos sendo: grupo A constituído por receptoras soronegativas que receberam embriões de doadoras soropositivas, grupo B por receptoras soronegativas que receberam embriões de doadoras soronegativas e grupo C com receptoras soropositivas que receberam embriões de doadoras soropositivas ou soronegativas para confirmar a transmissão vertical. As taxas de transmissão vertical nos grupos A, B e $\mathrm{C}$ foram $0 \%, 0 \%$ e $75 \%$, respectivamente, sendo esta diferença significativa $(\mathrm{p}<0,01)$. Segundo os autores, o procedimento de transferência de embrião proposto pela IETS, o qual inclui transferência para receptoras soronegativas, é um método efetivo para a produção de bezerros livres de infecção por N.caninum ao nascimento.

Barling et al. (2001) nos EUA, realizaram estudo para verificar se e quais práticas de manejo estavam associadas com prevalência de N.caninum em bezerros de corte. Foram utilizadas 76 propriedades com 1009 bezerros sendo examinados pelo NAT ( $\geq 80)$. A soroprevalência foi de $13 \%$ e em $59 \%$ das propriedades examinadas foi encontrado, no mínimo, um animal positivo. Neste estudo a prevalência não 
variou com o tamanho das propriedades. Entretanto, constituíram-se fatores de risco: período de nascimento dos bezerros, densidade animal, manutenção de animais em uma única área, permitindo parições e concentração de bovinos nesses locais, bem como de canídeos selvagens que têm acesso à ração aí presente. Também constituiuse fator de risco as novilhas criadas para reposição nas propriedades. Funcionaram como fatores de proteção o uso do cão no manejo dos bovinos e comedouros protegidos.

Hernandez, Risco e Donovan (2001) na Flórida, realizaram um estudo observacional prospectivo para determinar associação entre exposição ao $N$. caninum e a produção de leite em 565 vacas da raça Holandesa, as quais foram classificadas como soropositivas ou soronegativas sete dias após o parto, pelo uso de um ELISA cinético. A produção de leite foi comparada durante todo o período de lactação (305 dias), demonstrando uma queda de 3 a 4\% na produção, associado à exposição ao $N$. caninum. Os números também demonstraram que, uma queda na produção de leite de 800 libras por vaca em 305 dias de lactação, representou uma perda financeira de 128 dólares por vaca.

Corbellini et al. (2002) no Rio Grande do Sul, examinaram 223 amostras de sangue de vacas da raça Holandesa, pertencentes a cinco rebanhos. Essas amostras foram obtidas de vacas com ou sem registro de abortamentos e foram testadas através da RIFI ( $\geq 200)$. Do total, 11,2\% (25/223) foram soropositivas para $N$. caninum, com a soroprevalência sendo maior $(\mathrm{P}=0,0053)$ em vacas abortantes $(23,3 \%)$ do que em não abortantes $(8,3 \%)$. Foi observada associação entre soropositividade a $N$. caninum e abortamento, com vacas soropositivas apresentando 3,3 vezes mais chances de abortar do que as soronegativas (odds ratio $=3,33$; IC 95\%; 1,38 - 8,062). Todos os cinco rebanhos tiveram animais soropositivos, com a soroprevalência variando entre $3,1 \%$ e $30,7 \%$.

Sartor et al. (2005) no estado de São Paulo, examinaram, pelo $\operatorname{ELISA}(\geq 100), 913$ amostras de soro sangüíneo, sendo 505 de bovinos de corte e 408 de bovinos de leite, obtendo percentuais de $20,0 \%(101 / 505)$ e $35,5 \%(145 / 408)$ respectivamente.

Com o propósito de obterem informação mais precisa sobre as vias naturais de transmissão horizontal (pós natal) do N.caninum entre cães de fazenda e bovinos, Dijkstra et al. (2002) na Holanda, compararam 12 rebanhos leiteiros com evidência de infecção pós natal, com 21 rebanhos sem nenhuma evidência (rebanhos controle). Nos 12 rebanhos com evidência de infecção pós natal, uma média de soroprevalência de $48 \%$ (variação de $27 \%$ a $68 \%$ entre rebanhos) foi obtida. Para os 21 rebanhos controle foram adotados os seguintes critérios para serem selecionados: soroprevalência igual em todos os grupos de idade indicando que a transmissão pós natal foi a principal via de infecção, pelo menos um cão foi introduzido na propriedade dentro de um período de um ano e meio antes da colheita de sangue $\mathrm{e}$, durante os últimos dois anos a taxa anual de abortamento foi menor do que 3\% em novilhas e vacas entre 100 e 260 dias de gestação. Todos os animais em ambos os rebanhos eram da raça Holandesa e foram alojados em estábulos tipo freestall. Um questionário foi aplicado em todas as propriedades sobre aspectos da conduta dos cães, os quais eram suspeitos de serem relevantes na explicação de diferenças no risco para infecções pós natal entre os rebanhos controle e infectados pós natal. As questões contemplavam data de nascimento, ninhada, compra, venda e morte, visando a introdução de um cão na propriedade, além da alimentação do mesmo, local de defecação, acesso ás diferentes instalações de bovinos. Consumo de placenta, fetos abortados e descarga uterina em combinação com defecação no pasto e na silagem, foram observados em $19 \%$ (4/21) das fazendas controle e em $75 \%$ (9/ 12) das fazendas infectadas pós natal $\left(\mathrm{X}^{2}=10.01,1\right.$ d.f., $P=0,002$ ).

Segundo Jenkins et al. (2002), a presença de anticorpos específicos de $N$. caninum em fluídos fetais ou no soro sangüíneo da mãe podem ser úteis não somente no diagnóstico da infecção, mas também 
pode dar evidência para o possível papel que cada animal tem no ciclo de vida ou epidemiologia do $N$. caninum. Do mesmo modo, a demonstração de anticorpos específicos contra o parasita em um feto abortado, natimorto ou bezerro recém-nascido doente não permite uma conclusão definitiva ou inequívoca que o parasita foi responsável pela doença, porque a grande maioria dos bezerros infectados pelo $N$. caninum nascem saudáveis. Todavia, a demonstração que o feto desenvolveu anticorpos contra o $N$. caninum é, muitas vezes, a primeira indicação específica para a infecção fetal durante o processo de diagnóstico. Ainda, segundo os autores, um resultado sorológico positivo em uma única vaca que abortou somente sugere que o N. caninum estava envolvido no aborto, não propiciando diagnóstico conclusivo. Um diagnóstico mais definitivo pode ser conseguido quando o problema do aborto é examinado em nível de rebanho. O racional é determinar se a proporção de soropositividade em vacas que abortaram é maior do que em vacas que não abortaram. Alguns testes sorológicos tem sido validados para uso em grande número de populações bovina, abortando ou não, para detectar infecção por $N$. caninum usando um só título de ponto de corte (WILLIAMS et al., 1999) Uma alternativa altamente sensível e específica é utilizar o estado sorológico do bezerro recém nascido para determinar o verdadeiro estado de infecção da mãe, considerando que os anticorpos estão concentrados no colostro e desta maneira, os títulos no colostro são maiores do que no soro sangüíneo. Se o bezerro é positivo para anticorpos específicos de $N$. caninum, então a mãe está também infectada, desde que o bezerro tenha sido testado dentro de pouco tempo de nascido e tivesse mamado o colostro da própria mãe (STELUND et al., 1999). Esta alternativa é possível devido a alta eficiência de transmissão vertical e porque bezerros infectados via congênita tem títulos de anticorpos muito altos ao nascimento (DAVISON; OTTER; TREES, 1999).

\section{Neosporose em cães}

Casos de neosporose em cães têm sido relatados na América do Norte, Europa, África do Sul, Japão, Austrália e Costa Rica (DUBEY; LINDSAY, 1993; MORALES et al., 2001). A infecção adquirida através da via transplacentária é severa, caracterizando-se por encefalite, poliradiculite, polimiosite e paralisia dos membros posteriores (LINDSAY; DUBEY; DUNCAN, 1999). Atinge preferencialmente animais com até 12 meses de idade, provocando paralisia do tipo ascendente nos membros posteriores, sem predileção por sexo ou raça (RUEHLMANN et al., 1995). Além disso, dificuldade de deglutição, miocardite associada à morte súbita e pneumonia. A enfermidade pode ser localizada ou generalizada, com todos os órgãos envolvidos inclusive a pele, com severa dermatite. Neosporose cutânea foi descrita em cães com dermatite ulcerativa por Perl et al. (1998) em Israel e Poli et al. (1998) na Itália. Dubey, Koestner e Piper (1990) relataram a ocorrência de cistos de $N$. caninum em retina de quatro cães que adquiriram a doença via congênita.

Neosporose clínica em animais adultos é sugerido que ocorra em função da reativação de uma infecção anterior, associada com imunosupressão causada por vacinação com vírus atenuado (PATITUCCI et al.,1997). Barber, Payne-Johnson e Trees (1996) sugerem que o parasita pode ser encontrado em vários órgãos (coração, pulmões e fígado) durante a fase aguda e somente restrita ao SNC, na fase crônica. Os casos fatais tem sido relatados em animais com oito a 15 anos de idade e, cadelas com infecção subclínica transmitem para os seus fetos em sucessivas gestações. Apesar de predisposição a sexo e raça não serem conhecidos, a maioria dos casos descritos tem ocorrido com cães das raças Labrador, Boxer, Greyhound e Golden Retrievers.

$\mathrm{Na}$ Inglaterra, 163 soros de cães de diferentes raças foram examinados para a presença de anticorpos anti- $N$. caninum, através de RIFI, por Trees et al. (1993). Deste total, 27 (16,6\%) 
apresentaram títulos $\geq 50$ e 21 (12,9\%) tiveram títulos $\geq 200$, não havendo nenhuma sugestão de predisposição pela raça do animal.

Ainda na Inglaterra, Lathe (1994) examinou soro de 104 cães, para anticorpos anti N. caninum, através da RIFI, utilizando uma diluição de 1:50 como valor de título de ponto de corte, nos meses de fevereiro e março de 1994. A prevalência foi de 5,8\% (6 cães) e somente um animal mostrou sinais consistentes com neosporose clínica.

Na Dinamarca, Rasmussen e Jensen (1996) estimaram a prevalência de anticorpos para N.caninum em cães e, avaliaram associação entre alguns fatores de risco para a infecção. Amostras de soro foram obtidas de 98 cães, selecionados ao acaso, sem suspeita de neosporose. Para 87 cães foi aplicado um questionário, na época da colheita de sangue, o qual concedeu informações sobre raça, sexo, idade, utilização do cão em caçada, presença de outras espécies de animais na residência e alimentação (categorizada como comercial, caseira ou ambas). Para o teste foi utilizado uma RIFI comercial (VRMD, Inc. Washington, D.C.), usando uma diluição $\geq 1: 80$ para positividade. Títulos $\leq 80$ foram considerados negativos. Dos 98 animais testados, $13(13,3 \%)$ foram positivos a $1: 160$ e 2 $(2,1 \%)$ a $1: 320$, para N.caninum. No total, 15 cães $(15,3 \%)$ tiveram anticorpos contra o parasita. Não houve associação entre soropositividade e sexo, idade, uso do cão em caçada e dieta alimentar. Pelo cálculo da razão de chances (odds ratio) ficou evidente que a razão de cães tendo neosporose foi 3,46 (IC 95\%; 1,1 - 11,4) vezes maior entre cães regularmente expostos a gatos do que entre cães não expostos regularmente.

Wouda et al. (1999) na Holanda, analisaram a prevalência de anticorpos para $N$. caninum em cães de 109 fazendas em relação a prevalência em bovinos destas propriedades. Além disso, os autores compararam os dados de prevalência destes cães em relação aos cães do meio urbano. A soropositividade foi avaliada através do ELISA (título de ponto de corte de 0,4 ), tendo sido examinado 152 amostras de soro sangüíneo de cães de fazenda e 344 de cães urbanos. Entre os cães de fazenda 36 $(23,6 \%)$ foram soropositivos enquanto os cães urbanos apresentaram soropositividade para 19 $(5,5 \%)$ animais. Os autores observaram soroprevalência significativamente maior $(\mathrm{P}=0,01)$ em fêmeas $(14,1 \%)$ do que em machos $(6,8 \%)$, com a mesma aumentando com a idade. Em relação aos bovinos os dados de soroprevalência dos cães de fazenda correlacionaram fortemente com a alta prevalência de anticorpos em bovinos. Em propriedades sem presença de cães a soroprevalência em bovinos foi significativamente menor $(\mathrm{P}=0,0002)$ do que em propriedades onde cães estavam presentes.

Gondim et al. (2001) isolaram o N. caninum do cérebro de um cão da raça Collie, fêmea com 7 anos de idade, atendido por uma clínica particular do estado da Bahia, Brasil, com problema de incordenação e paresia de membros. A sorologia realizada através da RIFI apresentou um título de 1600. O animal sofreu eutanásia e, fragmentos do cérebro foram homogeneizados e inoculados em 9 gerbis, os quais foram sacrificados 3 a 4 meses após, e apresentaram cistos teciduais no cérebro. A confirmação para $N$. caninum foi feita através de IHC e PCR.

No Brasil, Mineo et al. (2001) investigaram a ocorrência de anticorpos para $N$. caninum em soro de 163 cães, os quais apresentaram desordens do tipo neuromuscular, respiratória e/ou gastrointestinal, através das técnicas de RIFI e IP (imunoprecipitação). Os autores utilizaram os títulos de 25 e 50 para RIFI e obtiveram índices de 2,5\% (4 cães) e 4,3\% (7 cães), respectivamente, totalizando um número de 11 animais $(6,7 \%)$ nas duas diluições utilizadas. Com relação a IP, dois antígenos fortemente dominantes (proteínas 29 e $35 \mathrm{kDa}$ ) foram reconhecidos nos 11 soros positivos para Neospora pela RIFI.

Em estudo realizado em propriedades rurais criadoras de ovinos, no município de Guarapuava, 
Paraná, Brasil, Romanelli (2002) examinou, pela RIFI, os soros de 24 cães que viviam nestas propriedades e encontrou $29 \%$ de animais soropositivos, com ponto de corte de 1:50.

Na Itália, Tarantino et al. (2001) relataram pela primeira vez um caso de infecção de pele, simultaneamente por Leishmania infantum e $N$. caninum, em um cão da raça Dogo Argentino com 9 meses de idade. As lesões, com aspecto de úlceras, ocorreram principalmente nos membros do animal e, fragmentos foram examinados através de exame histopatológico, microscopia eletrónica e imunohistoquímica. Além disso, foi realizada a sorologia, através de uma RIFI comercial, para anticorpos anti-L. infantum, T. gondii e N. caninum. Os exames histopatológicos mostraram intenso infiltrado inflamatório, principalmente de macrófagos, os quais continham protozoários intracelulares. A microscopia eletrônica confirmou a presença de $L$. infantum e N.caninum na pele do cão afetado. A IHC das amostras de pele mostrou numerosos macrófagos corados positivamente para $L$. infantum e fibroblastos para N. caninum. A RIFI para T. gondii foi negativa enquanto o título de anticorpos para $N$. caninum atingiu 800 e para L. infantum foi de 640 .

\section{Neosporose eqüina}

Dubey e Porterfield (1990) relataram o primeiro caso de neosporose em um feto eqüino abortado em 1985. A partir deste fato surgiram relatos de neosporose em fetos prematuros, animais recém nascidos e em animais adultos, manifestando as mais diversas lesões e conseqüente sintomatologia clínica.

Lindsay et al. (1996) observaram neosporose neonatal em uma fêmea de um mês de idade que apresentava cegueira bilateral. Na necropsia não foram observadas alterações macroscópicas, porém, microscopicamente encontrou-se um cisto de N.caninum ao redor da musculatura ocular. Este achado representa o primeiro relato de cisto tecidual do parasita fora do sistema nervoso central.
Gray et al. (1996) relataram o primeiro caso de neosporose visceral em uma égua com 10 anos de idade. As lesões estavam restritas ao intestino delgado e linfonodos mesentéricos, onde se observou a presença de taquizoítos. Daft et al. (1996) diagnosticaram neosporose em uma égua com 19 anos de idade apresentando sinais clínicos de disfagia, paresia de membros posteriores e alterações de comportamento. As lesões estavam no sistema nervoso central, nervos periféricos e miocárdio. Taquizoítos de N.caninum e cistos teciduais foram demonstrados por IHQ no cérebro, medula espinhal e nervos periféricos. Trata-se também do primeiro relato de cistos teciduais em nervos periféricos em qualquer espécie animal.

Marsh et al. (1996) isolaram em cultivo celular de cérebro e medula, organismos de $N$. caninum em um eqüino com sinais neurológicos.

Marsh et al. (1998) isolaram de tecido do sistema nervoso central de um eqüino da Califórnia um protozoário com características diferentes do $N$. caninum. Através da ultraestrutura encontraram o número de roptrias de 13 a 27 (média: 19), diferenciando do $N$. caninum com 8 a 18 roptrias (DUBEY; LINDSAY, 1996) e na análise molecular de uma pequena subunidade do gene de RNA ribossomal (ITS-1), encontraram sete nucleotídeos de diferentes bases entre $N$. caninum e o novo isolado. Embasados nestas diferenças, os autores propuseram uma nova espécie para este parasita denominando-a Neospora hughesi, parasita associado primariamente com mieloencefalites em eqüídeos. Somente os estágios assexuados são conhecidos. Os bradizoítos são englobados por uma parede cística e os taquizoítos residem dentro de um vacúolo parasitóforo no interior do citoplasma de células hospedeiras. Em alguns casos, os taquizoítos também podem apresentar-se diretamente no citoplasma da célula do hospedeiro. Em cultura, os taquizoítos apresentam divisão por endodiogenia. Quando fora das células apresentam aproximadamente 1,8 a 3,0 $\mathrm{mm}$ de largura e 4,0 a 7,0 mm de comprimento. 
Ciaramella et al. (2004), na Itália, realizaram o primeiro levantamento sorológico para anticorpos contra $N$. caninum (RIFI $\geq 50)$ em 150 eqüinos nascidos e criados naquele país, com anticorpos presentes em 42(28\%) animais. Os autores argumentaram que, devido a ocorrência de reação cruzada pela RIFI entre anticorpos contra $N$. caninum e N.hughesi, não foi possível identificar qual das espécies estava envolvida na infecção desses animais.

Locatelli-Dittrich et al. (2006), no sul do Paraná, investigaram a presença de anticorpos contra N.caninum, pela RIFI ( $\geq 50)$, em soros sangüíneo de éguas e potros descendentes antes da ingestão do colostro. Anticorpos foram detectados nos soros das éguas e potros, sugerindo a ocorrência de transmissão vertical nesta espécie.

\section{Neosporose ovina}

Dubey, Koestner e Piper (1990) avaliando um cordeiro recém-nascido que apresentava alterações neurológicas e veio a óbito com uma semana de vida, constataram através da IHQ e análise ultraestrutural dos cistos encontrados, que se tratava de uma infecção por N.caninum pela via transplacentária, sendo este o primeiro caso de N.caninum infectando naturalmente esta espécie animal.

Estudos sobre os efeitos da neosporose induzida em ovinos têm sido conduzidos usando N.caninum isolado de cães McAllister et al. (1996) demonstraram que infecções experimentais em início de gestação (65 dias), com $1,7 \times 10^{5}$ ou $1,7 \times 10^{6}$ taquizoítos, resultaram em abortamento em todos os casos, enquanto que infecções em gestações avançadas (120 dias) resultaram em animais clinicamente normais. Estes estudos provaram que o período de gestação é importante frente a uma infecção, indicando uma resposta imune por parte do feto no terço final da prenhez. Usando a IHQ, McAllister et al. (1996) encontraram cistos do protozoário em cérebro de $38 \%$ dos fetos abortados, enquanto que $39 \%$ dos animais infectados congênitamente apresentaram-se clinicamente normais. Semelhante ao que ocorre na infecção natural, os cistos não foram encontrados fora do SNC (sistema nervoso central).

Jolley et al. (1999) observaram abortamentos, sintomatologia clínica e achados histopatológicos em fetos de ovelhas que haviam sido infectadas experimentalmente por N.caninum no início da vida reprodutiva, mostrando a ação do parasita ao longo de várias gestações.

Infecções congênitas experimentais com N.caninum em ovinos podem induzir ao abortamento, nascimento precoce ou neonatos clinicamente normais, semelhante ao que ocorre nas infecções naturais em bovinos (MARKS, 1999). A distribuição dos cistos e lesões também são semelhantes às descritas em bovinos. Neosporose induzida experimentalmente em ovinos parece ser um bom modelo de estudo da neosporose em rebanho (MARKS, 1999).

Em um dos únicos estudos realizados com N.caninum em ovinos objetivando dados de prevalência em infecção natural, Otter et al. (1997) analisaram anticorpos contra N.caninum pela RIFI em 129 amostras de fluido pleural de 141 cordeiros abortados, não examinados histologicamente, e todas foram negativas.

No Brasil, Figliuolo et al. (2004), examinaram, pela RIFI ( $\geq 50), 597$ amostras de soro sangüíneo de ovinos, observado uma soropositividade de $9,2 \%$ para anticorpos contra $N$. caninum.

Kobayashi et al. (2001) constataram o primeiro caso de infecção natural pelo N.caninum acometendo uma ovelha prenhe e seus dois fetos gêmeos.

Recentemente, Romanelli (2002) realizou um estudo soro-epidemiológico no município de Guarapuava, Paraná, Brasil, utilizando a RIFI em 305 soros de ovinos e encontrou $9,5 \%$ de animais soropositivo, com ponto de corte de 1:100.

Apesar dos estudos sobre a neosporose realizados até o momento, torna-se ainda necessário elucidar 
aspectos epidemiológicos ligados especialmente à mecanismos de transmissão, da resposta imune e diagnóstico, além do caráter zoonótico desta importante enfermidade parasitária ligada à reprodução animal.

\section{Referências}

ABBIT, B.; CRAIG, T. M.; JONES, L. P.; HUEY, R. L.; EUGSTER, K. Protozoal abortion in a herd of cattle concurrently infected with Hammondia pardalis. Journal of the American Veterinary Medical Association, Schaumburg, v.3, p.444-448, 1993.

AGERHOLM, J. S.; BARR, B. C. Bovine abortions associated with Neospora in Denmark. Acta Veterinaria Scandinavica, Copenhagen, v.35, n.4, p.461-464, 1994.

ANDERSON, M. L.; ANDRIANAVIRO, A. G.; CONRAD, P. A. Neosporosis in cattle. Animal Reproduction Science, Amsterdam, v.2, n.60/61, p.417-431, 2000.

ANDERSON, M. L.; BARR, B. C.; CONRAD, P. A. Protozoal causes of reproductive failure in domestic ruminants. Veterinary Clinical American Food Animal, Philadelphia, v.10, n.3, p.439-461, 1994.

ANDERSON, M. L.; REYNOLDS, J. P.; ROWE, J. D.; SVERLOW, K. M.; PACKHAM, A. E.; BARR, B. G.; CONRAD, P. A. Evidence of vertical transmission of Neospora infection in dairy cattle. Journal of the American Veterinary Medical Association, Schaumburg, v.210, n.8, p.1169-1172, 1997.

BAILLARGEON, P.; FECTEAU, G.; PARÉ, J.; LAMOTHE, P.; SAUVÉ, R. Evaluation of the embryo transfer procedure proposed by the International Embryo Transfer Society as a method of controlling vertical transmission of Neospora caninum in cattle. Journal of the American Veterinary Medical Association, Schaumburg, v.218, n.11, p.1803-1806, 2001.

BARBER, J. S.; PAYNE-JOHNSON, C. E.; TREES, A J. Distribution of Neospora caninum within the central nervous system and other tissues of six dogs with clinical neosporosis. Journal of Small Animal Practice, Oxford, v.37, n.12, p.568-574, 1996.

BARLING, K. S.; McNEILL, J. W.; PASCHAL, J. C.; McCOLLUM III, F. T.; CRAIG, T. M.; ADAMS, L. G.; THOMPSON, J. A. Ranch - management factors associated with antibody seropositivity for Neospora caninum in consignments of beef calves in Texas, USA. Preventive Veterinary Medicine, Amsterdam, v.52, n.1, p.53-61, 2001.

BARR, B. C.; CONRAD, P. A.; BREITMEYER, R.; SUERLOW, K.; ANDERSON, M. L.; REINOLDS, J.; CHAUVET, A. E.; DUBEY, J.P.; ARDANS, A. A. Congenital
Neospora infection in calves born from cows that had previously aborted Neospora-infected fetuses: four cases (1990-1992). Journal of the American Veterinary Medical Association, Schaumburg, v.202, n.1, p.113-117, 1993.

BARTELS, C. J. M.; WOUDA, W.; SCHUKKEN, Y. H. Risk factors for Neospora caninum-associated abortion storms in dairy herds in the Netherlands (1995 a 1997). Theriogenology, Stoneham, v.52, n.2, p.247-257, 1999.

BASSO, W.; VENTURINI, L.; VENTURINI, M. C.; HILL, D. E.; KWOK, O. C. H.; SHEN, S. K.; DUBEY, J. P. First isolation of Neospora caninum from the feces of a naturally infected dog. Journal of Parasitology, Lawrence, v.87, n.3, p.612-618, 2001.

BJERKAS, I.; MOHN, S. F.; PRESTHUS, J. Undentified cyst-forming sporozoan causing encephalomyelite and myositis in dogs. Zeithschrift Fuer Parasitenkunde, Berlin, v.70, n.2, p.271-274, 1984.

BJÖRKMAN, C.; JOHANSSON, O.; STELUND, S.; HOLMDAHL, O. J. M.; UGGLA, A. Neospora species infection in a herd of dairy cattle. Journal of the American Veterinary Medical Association, Schaumburg, v.208, n.9, p.1441-1444, 1996.

CAMPERO, C. M.; ANDERSON, M. L.; CONOSCIUTO, G.; ODRIOZOLA, H.; BRETSCHENEIDER, G.; POSO, M. A. Neospora caninum-associated abortion in a dairy herd in Argentina. Veterinary Record, London, v.143, n.8, p.228229, 1998.

CIARAMELLA, P.; CORONA, M.; CORTESE, L.; PIANTEDOSI, D.; SANTORO, D.; LORIA, A. D.; RIGATO, R. Seroprevalence of Neospora spp. in asymptomatic horses in Italy. Veterinary Parasitology, Amsterdam, v.123, p.11-15, 2004.

CONRAD, P. A.; BARR, B. C.; SVERLOW, K. W.; ANDERSON, M.; DAFT, B.; KINDE, H.; DUBEY, J. P.; MUNSON, L.; ARDANS, A. In vitro isolation and characterization of a Neospora sp. from aborted bovine foetuses. Parasitology, Cambridge, v.106, n.3, p.239-249, 1993.

CORBELLINI, L. G.; DRIEMEIER, D.; CRUZ, C. F. E.; GONDIM, L. F. P.; WALD, V. Neosporosis as a cause of abortion in dairy cattle in Rio Grande do Sul, southern Brazil. Veterinary Parasitology, Amsterdam, v.103, n.3, p.195-202, 2002.

DAVISON, H. C.; OTTER, A.; TREES, A. J. Estimation of vertical and horizontal transmission parameters of Neospora caninum infections in dairy cattle. International Journal for Parasitology, Oxford, v.29, n.10, p.1683-1689, 1999.

DIJKSTRA, T. H.; BARKEMA, H. W.; EYSKER, M.; HESSELINK, J. W.; WOUDA, W. Natural transmission routes of Neospora caninum between farm dogs and cattle. Veterinary Parasitology, Amsterdam, v.105, n.2, p.99-104, 2002. 
DUBEY, J.P. Toxoplasma, Neospora, Sarcocystis and other cystforming coccidia of humans and animals In: KREIER, J.P.Parasitic protozoa. New York: Academic Press, 1993.p.1-158.

DUBEY, J. P.; PORTERFIELD, M. L. Neospora caninum (Apicomplexa) in an aborted equine fetus. Journal of Parasitology, Lawrence, v.76, n.5, p.732-734, 1990.

DUBEY, J. P.; HATTEL, A. L.; LINDSAY, D. S.; TOPPER, M. J. Neonatal Neospora caninum infection in dogs: isolation of the causative agent and experimental transmission. Journal of the American Veterinary Medical Association, Schaumburg, v.193, n.10, p.1259$1263,1988$.

DUBEY, J. P.; KOESTNER, A.; PIPER, R. C. Repetead transplacental transmission of Neospora caninum in dogs. Journal of the American Veterinary Medical Association, Schaumburg, v.197, n.7, p.857-860, 1990.

DUBEY, J. P.; LINDSAY, D. S. A review of Neospora caninum and neosporosis. Veterinary Parasitology, Amsterdam, v.67, n.1/2, p.1-59, 1996.

DUBEY, J. P.; LINDSAY, D. S. Neosporosis. Parasitology Today, Amsterdam, v.9, n.12, p.452-458, 1993.

DUBEY, J. P.; LINDSAY, D. S.; ADAMS, D. S.; GAY, J. M.; BASZLER, T. V.; BLAGBURN, B. L.; THULLIEZ, P. Serologic responses of cattle and other animals infected with Neospora caninum. American Journal of Veterinary Research, Chicago, v.57, n.3, p.329-336, 1996.

DUBEY, J. P.; SCHARES, G. Diagnosis of bovine neosporosis. Veterinary Parasitology, Amsterdam, v.140, n.1/2, p.1-34, aug. 2006.

DUIVENVOORDEN, J. Neospora abortion in eastern Ontario dairy herds. Canadian Veterinary Journal, Ottawa, v.36, p.623, 1995.

FIGLIUOLO, L. P. C.; KASAI, N.; RAGOZO, A. M. A.; DE PAULA, V. S. O.; DIAS, R. A.; SOUZA, S. L. P.; GENNARI, S. M. Prevalence of anti-Neospora caninum antibodies in ovine from São Paulo State, Brazil. Veterinary Parasitology, Amsterdam, v.123, n.3/4, p.161-166, sep. 2004.

FONDEVILA, D.; AÑOR, S.; PUMAROLA, M.; DUBEY, J. P. Neospora caninum identification in an aborted bovine fetus in Spain. Veterinary Parasitology, Amsterdam, v.77, n.2/3, p.187-189, 1998.

GONDIM, L. F. P.; McALLISTER, M. M.; PITT, W. C.; ZEMLICKA, D. E. Coyotes (Canis latrans) are definitive hosts of Neospora caninum. International Journal for Parasitology, Oxford, v.34, n.2, p.159-161, feb. 2004.

GONDIM, L. F. P.; SARTOR, I. F.; HASEGAWA, M.; YAMANE, I. Seroprevalence of Neospora caninum in dairy cattle in Bahia, Brazil. Veterinary Parasitology, Amsterdam, v.86, n.1, p.71-75, 1999.
GONDIM, L. P. F.; PINHEIRO, A. M.; SANTOS, P. O. M.; JESUS, E. E. V.; RIBEIRO, M. B.; FERNANDES, H. S.; ALMEIDA, M. A. O.; FREIRE, S. M.; MEYER, R.; McALLISTER, M. M. Isolation of Neospora caninum from the brain of a naturally infected dog, and production of encysted bradyzoites in gerbils. Veterinary Parasitology, Amsterdam, v.101, p.1-7, 2001.

GONZALES, L.; BUXTON, D.; ATXAERANDIO, R.; ADURIZ, G.; MALEV, S.; MARCO, J. C.; CUERVO, L. A. Bovine abortion associated with Neospora caninum in northern Spain. Veterinary Record, London, v.144, n.6, p.145-150, 1999.

GOTTSTEIN, B.; HENTRICH, B.; WYSS, R.; THUR, B.; BRUCKNER, L.; MULLER, N.; KAUFMAN, H.; WALDVOGEL, A. Molecular and immunodiagnosis of bovine neosporosis in Switzerland. Schweizer Archive für Tierheilkunde, Bern, v.141, n.2, p.59-68, 1999.

GRAY, M. L.; HARMON, B. E.; SALES, L.; DUBEY, J. P. Visceral neosporosis in a 10-year-old horse. Journal of Veterinary Diagnostic Investigation, Columbia, v.8, n.1, p.130-133, jan. 1996.

GUIMARÃES JUNIOR, J. S.; SOUZA, S. L. P.; BERGAMASCHI, D. P.; GENNARI, S. M. Prevalence of Neospora caninum antibodies and factors associated with their presence in dairy cattle of the north of Paraná state, Brazil. Veterinary Parasitology, Amsterdam, v.124, p.1-8, 2004.

HEMPHILL, A.; GOTTSTEIN, B.; KAUFMANN, H. Adhesion and invasion of bovine endothelial cells by Neospora caninum. Parasitology, Cambridge, v.112, n.2, p.183-197, 1996.

HERNANDEZ, J.; RISCO, C.; DONOVAN, A. Association between exposure to Neospora caninum and milk production in dairy cows. Journal of the American Veterinary Medical Association, Schaumburg, v.219, n.5, p.632-635, 2001.

HIETALA, S. K.; THURMOND, M. C. Posnatal Neospora caninum transmission and transient serologic responses in two dairies. International Journal for Parasitology, Oxford, v.29, n.10, p.1669-1676, 1999.

HOAR, B. R.; RIBBLE, C. S.; SPITZER, C. C.; SPITZER, P. G.; JANZEN, E. D. Investigation of pregnancy losses in beef cattle herds associated with Neospora sp infection. Canadian Veterinary Journal, Ottawa, v.37, n.6, p.364366, jun. 1996.

HOLMDAHL, O. J. M.; BJÖRKMAN, D.; UGGLA, A. A case of Neospora associated bovine abortion in Sweden. Acta Veterinaria Scandinavica, Copenhagen, v.36, p.279281, 1995.

HORNOK, S.; NASLUND, K.; HAJTOS, I.; TANYI, J.; TEKES, L.; VARGA, I.; UGGLA, A.; BJÖRKMAN, C. 
Detection of antibodies to Neospora caninum in bovine post abortion blood samples from Hungary. Acta Veterinaria Hungarica, Budapest, v.46, n.4, p.431-436, 1998.

HUONG, L. T. T.; LJUNGSTRÖM, B. L.; UGGLA, A.; BJÖRKMAN, C. Prevalence of antibodies to Neospora caninum and Toxoplasma gondii in cattle and water buffaloes in southern Vietnam. Veterinary Parasitology, Amsterdam, v.75, n.1, p.53-57, 1998.

JENKINS, M. C.; CAVER, J. A.; BJÖRKMAN, C.; ANDERSON, T. C.; ROMAND, S.; VINYARD, B.; UGGLA, A.; THULLIEZ, P.; DUBEY, J. P. Serological investigation of an outbreak of Neospora caninum-associated abortion in a dairy herd in southeastern United States. Veterinary Parasitology, Amsterdam, v.94, n.1/2, p.17-26, 2000.

JENKINS, M.; BASZLER, T.; BJÖRKMAN, C.; SCHARES, G.; WILLIAMS, D. Diagnosis and seroepidemiology of Neospora caninum-associated bovine abortion. International Journal for Parasitology, Oxford, v.32, n.5, p.631-636, 2002.

JOLLEY, W. R.; McALLISTER, M. M.; McGUIRE, A. M.; WILLS, R. A. Repetitive abortion in Neospora-infected ewes. Veterinary Parasitology, Amsterdam, v.82, n.3, p.251-257, apr. 1999.

KOBAYASHI, Y.; YAMADA, M.; OMATA, Y.; KOYAMA, T.; SAITO, A; MATSUDA, T.; OKUYAMA, K.; FUJIMOTO, S.; FURUOKA, H.; MATSUI, T. Neospora caninum infection in a adult sheep and her twin fetuses. Journal of Parasitology, Lawrence, v.87, n.2, p.434-436, 2001.

LATHE,C. L. Neospora caninum in British dogs. Veterinary Record, London, v.134, n.20, p.532, 1994.

LINDSAY, D. S.; DUBEY, J.P.; COLE, R. A.; NUEHRING, L. P.; BLAGBURN, B. L. Neospora-induced protozoal abortion in cattle. The Compendium on Continuing Education for the Practicing Veterinarian, Princeton, v.15, n.6, p.882-889, 1993.

LINDSAY, D. S.; DUBEY, J. P.; DUNCAN, R. B. Confirmation that dogs are definitive host for Neospora caninum. Veterinary Parasitology, Amsterdam, v.82, n.4, p.327-333, 1999.

LINDSAY, D. S.; STEINBERG, H.; DUBIELZIG, R. R.; SEMRAD, S. D.; KONKLE, D. M.; MILLER, P. E.; BLAGBURN, B. L. Central nervous system neosporosis in a foal. Journal Veterinary Diagnostic Investigation, Columbia, v.8, n.4, p.507-510, 1996.

LOCATELLI-DITTRICH, R.; DITTRICH, J. R.; RICHARTZ, G. M. E.; ANTUNES, J.; PINCKNEY, R. D.; DECONTO, I.; HOFFMANN, D. C. S.; THOMAZ-SOCCOL, V. Investigation of Neospora sp. and Toxoplasma gondii antibodies in mares and precolostral foals from Paraná State, Southern Brazil. Veterinary Parasitology, Amsterdam, v.135, n.3/4, p.215-221, feb. 2006.
MARKS, J. Immunity to Neospora caninum. 1999. Tese $(\mathrm{PhD})$ - University of Edinburgh, Edimburgo.

MARSH, A. E.; BARR, B. C.; MADIGAN, J. E.; CONRAD, P. A. In vitro cultivation and characterization of a Neospora isolate obtained from a horse with protozoal myeloencephalitis. In: AMERICAN SOCIETY PARASITOLOGY AND THE SOCIETY OF PROTOZOOLOGISTS, n., Arizona, 1996. Proceedings... Arizona: editora, 1996. Abstract, 114.

MARSH, A. E.; BARR, B. C.; PACKAM, A. E.; CONRAD, P. A. Description of a new Neospora species ( Protozoa: Apicomplexa: Sarcocystidae). Journal of Parasitology, Lawrence, v.84, n.5, p.983-991, 1998.

McALLISTER, M. M.; LINDSAY, D. S.; JOLLEY, W. R.; WILLS, R. A.; McGUIRE, A. M; TRESS, A. J.; STOBART, R. H. Experimental neosporosis in pregnant ewes and their offspring. Veterinary Pathology, Washington, v.33, n.6, p.647-655, nov. 1996.

McALLISTER, M. M.;DUBEY,J.P.; LINDSAY,D. S.;JOLLEY, W. R.; WILLS, R. A.; McGUIRE, A. Dogs are definitive hosts of Neospora caninum. International Journal for Parasitology, Oxford, v.28, n.9, p.1473-1478, 1998.

McALLISTER, M. M.; HUFFMAN, E. M.; HIETALA, S. K.; CONRAD, P. A.; ANDERSON, M. L.; SALMAN, M. O. Evidence suggesting a point source exposure in an outbreak of bovine abortion due to neosporosis. Journal of Veterinary Diagnostic Investigation, Oxford, v.8, n.3, p.355-357, 1996.

McNAMEE, P. T.; JEFFREY, M. Neospora-associated bovine abortion in northern Ireland. Veterinary Record, London, v.134, p.48, 1994.

MINEO, T. W. P.; SILVA, D. A. O.; COSTA, G. H. N.; VON ANCKEN, A. C. B.; KASPER, L. H.; SOUZA, M. A.; CABRAL, D. D.; COSTA, A. J.; MINEO, J. R. Detection of IgG antibodies to Neospora caninum in dogs examined in a veterinary hospital from Brazil. Veterinary Parasitology, Amsterdam, v.98, n.4, p.239-245, jul. 2001.

OGAWA, L.; NAVARRO, I. T.; FREIRE, R. L.; OLIVEIRA, R. C. de; VIDOTTO, O. Ocorrência de Anticorpos AntiToxoplasma gondii em ovinos da microrregião de Londrina no Estado do Paraná. Semina, Londrina, v. 24, n. 1, p. 57 62, 2003 .

O'TOOLE, D.; JEFFREY, M. Congenital sporozoan encephalomyelitis in a calf. Veterinary Record, London, v.121, n.24, p.563-566, 1987.

OTTER, A.; JEFFREY, M.; GRIFFITHS, I. B.; DUBEY, J. P. A survey of the incidence of N.caninum infection in aborted and stillborn bovine fetuses in England and Walles. Veterinary Record, London, v.136, n.24, p.602606, jun. 1995.

OTTER, A.; WILSON, B. W.; SCHOLES, S. F. E.; JEFFREY, M.; HELMICK, B.; TREES, A. J. Results of a survey to determine whether Neospora caninum is a significant 
cause of ovine abortion in England and Wales. Veterinary Record, London, v.140, n.7, p.175-177, feb. 1997.

PARÉ, J.; FECTEAU, G.; FORTIN, M.; MARSOLAIS, G. Seroepidemiologic study of Neospora caninum in dairy herds. Journal of the American Veterinary Medical Association, Schaumburg, v.213, n.11, p.1595, 1998.

PARÉ, J.; THURMOND, M. C.; HIETALA, S. K. Neospora caninum antibodies in cows during pregnancy as a predictor of congenital infection and abortion. Journal of Parasitology, Lawrence, v.83, n.1, p.82-87, feb. 1997.

PARISH, S. M.; MAAG-MILLER, L.; BESSER, T. E.; WEIDNER, J. P.; McELWAIN, T.; KNOWLES, D. P.; LEATHERS, C. W. Myelitis associated with protozoal infection in newborn calves. Journal of the American Veterinary Medical Association, Schaumburg, v.191, n.12, p.1599-1600, 1987.

PATITUCCI, A. N.; ALLEY, M. R.; JONES, B. R.; CHARLESTON, W. A. Protozoal encephalomyelitis of dogs involving Neospora caninum and Toxoplasma gondii in New Zealand. New Zealand Veterinary Journal, Wellington, v.45, n.6, p.231-235, 1997.

PERL, S.; HARRUS, S.; SATUCHNE, C.; YAKOBSON, B.; HAINES, D. Cutaneous neosporosis in a dog in Israel. Veterinary Parasitology, Amsterdam, v.79, n.3, p.257-261, 1998.

PICOUX, J. B.; ADLER, C.; CHASTANT, S.; MILLEMANN, Y.; REMY, D. La neosporose bovine: une cause mafeure d'avortement? Bulletin de la Sociedad Véterinary Practice de France, Paris, v.82, n.4, p.177-201, 1998.

POLI, A.; MANCIANTI, F.; CARLI, M. A.; STROSCIO, M. C.; KRAMER, L. Neospora caninum infection in a Bernese cattle dog from Italy. Veterinary Parasitology, Amsterdam, v.78, n.2, p.79-85, 1998.

RASMUSSEN, K.; JENSEN, A. L. Some epidemiologic features of canine neosporosis in Denmark. Veterinary Parasitology, Amsterdam, v.62, n.3/4, p.345-349, 1996.

RUEHLMANN,D.; PODDEL, M.; OGLESBEE, M.; DUBEY, J. P. Canine neosporosis: a case report and literature review. Journal American Animal Hospital Association, Lakewood, v.31, n.2, p.174-183, 1995.

SARTOR,I.F.; GARCIAFILHO,A.; VIANNA,L.C.; PITUCO, E. M.; DAL PAI, V.; SARTOR, R. Ocorrência de antocorpos anti-Neospora caninum em bovinos leiteiros e de corte da região de Presidente Prudente, SP. Arquivo do Instituto Biológico, São Paulo, v.72, n.4, p.413-418, 2005.

SAWADA, M.; KONDO, H.; TOMIOKA, Y.; PARK, C. H.; MORITA, T.; SHIMADA, A.; UMEMURA, T. Isolation of Neospora caninum from the brain of a naturally infected adult dairy cow. Veterinary Parasitology, Amsterdam, v.90, n.3, p.247-252, 2000.
SHIVAPRASAD, H. L.; ELY, R.; DUBEY, J. P. Neosporalike protozoan found in an aborted bovine placenta. Veterinary Parasitology, Amsterdam, v.34, p.145-148, 1989.

SPEER, C. A.; DUBEY, J. P. Ultraestruture of tachyzoites, bradyzoites, and tissue cysts of Neospora caninum. The Journal of Protozoology, Lawrence, v.36, p.458-463, 1989.

STELUND, S.; KINDAHL, H.; MAGNUSSON, U.;UGGLA, A.; BJÖRKMAN, C. Serum antibody profile and reproductive performance during two consecutive pregnancies of cows naturally infected with Neospora caninum. Veterinary Parasitology, Amsterdam, v.85, n.4, p.227-234, 1999.

TARANTINO, C.; ROSSI, G.; KRAMER, L. H.; PERRUCCI, S.; CRINGOLI, G.; MACCHIONI, G. Leishmania infantum and Neospora caninum simultaneous skin infection in a dog in Italy. Veterinary Parasitology, Amsterdam, v.102, n.1/2, p.77-83, dec. 2001.

THILSTED, J. P.; DUBEY, J. P. Neosporosis-like abortions in a herd of dairy cattle. Journal Veterinarian Diagnostic Investigation, Columbia, v.1, n.3, p.205-209, 1989.

THORNTON, R. N.; GAJADHAR, A.; EVANS, J. Neospora abortion epidemic in a dairy herd. New Zealand Veterinary Journal, Wellington, v.42, n.5, p.190-191, oct. 1994.

THURMOND, M. C.; ANDERSON, M. L.; BLANCHARD, P. C. Secular and seasonal trends of Neospora abortion in California dairy cows. Journal of Parasitology, Lawrence, v.81, n.3, p.364-367, jun. 1995.

TREES, A. J.; GUY, F.; TENNANT, B. J.; BALFOUR, A. H.; DUBEY, J. P. Prevalence of antibodies to Neospora caninum in a population of urban dogs in England. Veterinary Parasitology, Amsterdam, v.132, n.6, p.125-126, 1993.

WILLIAMS, D. J. L.; DAVISON, H. C.; HELMICK, B.; McGARRY, J.; GUY, F.; OTTER, A.; TREES, A. J. Evaluation of a commercial ELISA for detecting serum antibody to Neospora caninum in cattle. Veterinary Record, London, v.145, p.571-575, 1999.

WOUDA, W.; DIJKSTRA, T.; KRAMER, A. M. H.; VAN MAANEN, C.; BRINKHOF, J. M. A. Seroepidemiological evidence for a relationship between Neospora caninum infections in dogs and cattle. International Journal for Parasitology, Lawrence, v.29, n.10, p.1677-1682, 1999.

WOUDA, W.; MOEN, A. R.; VISSER, I. J. R.; VAN KNAPEN, F. Bovine fetal neosporosis: a comparison of epizootic and sporadic abortion cases and different age classes with regard to lesion severity and immunohistochemical identification of organisms in brain, heart, and liver. Journal Veterinary Diagnostic Investigation, Oxford, v.9, n.2, p.180-185, apr. 1997.

YAMANE, I.; KOKUHO, T.; SHIMURA, K.; ETO, M.; SHIBARA, T.; HARITANI, M.; OUCHI, Y.; SVERLOW, K.; CONRAD, P. A. In vitro isolation and characterisation of a bovine Neospora species in Japan. Research Veterinary Science, London, v.63, n.1, p.77-80, jul./aug. 1997. 